\title{
LEER Y EDITAR A GÓNGORA EN EL SIGLO DE ORO: MARTÍN DE ANGULO O LA FORJA (FRUSTRADA) DE UN CANCIONERO DE AUTOR
}

\author{
FrANCISCO J. EsCOBAR \\ Universidad de Sevilla \\ fescobar@us.es
}

A tendiendo a las diferentes formalizaciones identificables en los cancioneros del Siglo de Oro, se hace cada vez más necesario investigar sus aspectos formales, morfológicos y estructurales desde variadas perspectivas, esto es, ecdótica, naturaleza genológica, musical, editorial, como recopilación colectiva o individual ${ }^{1} \ldots$ Pues bien, habida cuenta de tan disímiles modalidades genéricas de cancionero, me propongo analizar en estas páginas la singular compilación de poemas de Luis de Góngora que llevó a cabo un comentarista y editor frustrado del ilustre cordobés, Martín de Angulo y Pulgar, en un manuscrito autógrafo suyo un tanto olvidado ${ }^{2}$. De hecho, se trata de un cancionero de autor facticio, in fieri y misceláneo, dado que brinda numerosos poemas de Góngora, a modo de cancionero-antología, con el objeto de enaltecer sus cualidades estéticas y contribuir, en suma, a su canonización en el parnaso áureo o república de las letras. En general, sigue la estela, también frustrada, del manuscrito Chacón pero tratando de superar al tiempo, si bien con una notoria voluntad estética e imaginación creativa, las ediciones del XVII (Gonzalo de Hoces, Vicuña...).

\footnotetext{
1 Este trabajo de investigación queda enmarcado en el Proyecto de investigación: «Del sujeto a la institución literaria en la Edad Moderna: procesos de mediación», Universidad de Sevilla, bajo la dirección de Juan Montero e Isabel Román.

2 Sobre este autor ha realizado su tesis doctoral Juan Manuel Daza (2015), con un detallado estado de la cuestión. En esta voluntad de reivindicar el análisis de la obra integral de dicho comentarista, preparo el estudio y edición de la Égloga fúnebre en el Proyecto de investigación: «Édition digitale et étude de la polémique autour de Góngora», Université de Paris-Sorbonne, bajo la dirección de M. Blanco.
}

Edad de Oro, XXXVII (2018), pp. 96-118, ISSN: 0212-0429 - ISSNe: 2605-3314 
Además, para su empresa, Angulo trabajó en diálogo intertextual con prestigiosos círculos de élite cultural de fuste gongorino que, como un corifeo orquestado o acción colegiada, contribuyeron de alguna forma a la forja de este cancionero de autor, o cancionero colectivo según se mire, para homenajear a Góngora y difundir así su poesía en la década de los treinta. Se trataría, en fin, de un proyecto similar, salvando las distancias, al del pintor Francisco Pacheco y Francisco de Rioja respecto a la edición de Versos de Fernando de Herrera: emendados y divididos por él en tres libros (1619), con la salvedad de que el de Angulo no llegó a buen puerto editorial.

Me centraré, por tanto, en lo que hace al plano epistemológico y de orden metodológico, en las siguientes perspectivas y categorías conceptuales, a saber, aspectos de caracterización genérica, morfológicos, formales, estructurales, editoriales y de recopilación individual. Para ello, me ceñiré a esta disposición expositiva, al servicio de una debida argumentación analítica, con el objeto de ofrecer unos resultados finales y conclusiones, acompañadas de futuras líneas abiertas para la discusión y debate:

1. Un manuscrito de poesías varias o un género editorial frustrado: caracterización genérica y morfológica

2. Contenido y estructura

3. Análisis del contenido

3.1. Notas biográficas de Góngora y circunstancias compositivas

3.2. Góngora entre la realidad y la ficción: voz de la enunciación poética y sermocinatio

3.3. La imagen poética de Góngora entre el reflejo, el vislumbre y el fulgor: la retórica visual de Angulo

3.4. Fronteras entre los géneros poéticos: hibridación

3.5. Labor de Angulo como editor, comentarista e intérprete: hacia el género del centón

3.3.1. Referencias intratextuales

3.3.2. Referencias intertextuales (e interpersonales)

4. A modo de conclusión

1. UN MANUSCRITO DE POESÍAS VARIAS O UN GÉNERO EDITORIAL FRUSTRADO: CARACTERIZACIÓN GENÉRICA Y MORFOLÓGICA

El manuscrito autógrafo Varias poesías y casi todas las que compuso... D. Luis de Góngora, de Angulo y Pulgar, Fundación Bartolomé March (B87-V3-10), de 330 folios, fue compuesto en distintas fases de redacción con tinta negra, en su mayor 
parte, y roja, al tiempo que presenta titulillos, reclamos, epígrafes, argumentos, notas y algunas ilustraciones. Para estas, el erudito contó con la colaboración de Jean de Courbes y Francisco Heylan como acceso al autor y ordinatio, eso sí, sin preliminares y posliminares de naturaleza textual ${ }^{3}$. En el códice se identifican igualmente enmiendas, apostillas supra lineam y espacios en blanco con la intención de transcribir poemas que no se llegaron a copiar. En definitiva, estamos ante una edición truncada, si bien destaca su inacabado aparato de notas como comento y glosa a los poemas, arropado de argumentos a modo de contextualización preliminar.

Por otra parte, el códice deja ver en ocasiones variantes redaccionales, sean del texto de Góngora o del editor; otras veces, en cambio, se plantean más bien problemas de interpretación de pasajes o loci critici por parte de Angulo en calidad de lector tanto de las ediciones consagradas al cordobés, con frecuencia con el objeto de enmendar la plana, como de comentaristas de la altura de José de Pellicer, Salcedo Coronel y Salazar Mardones. Asimismo, se hace eco de la vindicación de Góngora por parte del Abad de Rute, a quien recuerda en Del Zéphiro (Apéndice, f. 249v) como lector de su Didascalia multiplex ${ }^{4}$, Francisco de Amaya y Pedro Díaz de Rivas. Por último, especial realce merecen algunas notas eruditas de aliento ensayístico relacionadas con la polémica a propósito de los retratos satíricos (o caricaturas) de Quevedo por Góngora, con la censura paródica de su traslación de las Anacreónticas. Del mismo modo, presta atención nuestro comentarista al estilo «claro» de Lope de Vega, por su Arcadia, Jerusalén conquistada y Dragontea, con pátina de polémica literaria, o al hilo de la expresión popular Esto es de Lope, frente al «culto» inventado por el ilustre cordobés. No falta tampoco el Orfeo de Jáuregui y su acerado juicio crítico contra las Soledades.

\section{CONTENIDO Y ESTRUCTURA}

Si se atiende a la esmerada encuadernación del códice, el lector puede hallar como pórtico de entrada el ex libris de Bartolomé March: «BM non ego argento sed argentum bono et amicis meis». Seguidamente, tras dos folios y medio en blanco, se accede a los siguientes contenidos, que paso a resumir de manera sintética:

f. 1r: Varias poesías i casi todas las que compuso aquel ilustre, ingeniosíssimo, erudito i doctíssimo varón D. Luis de Góngora, natural de la ciudad de Córdova, racionero de su Santa Iglesia, capellán de las S. C. y R. Magestades de D. Filipe

3 A partir de este códice citaré los textos conservando sus caracteres grafemáticos pero modernizando tanto el empleo de mayúsculas como de la puntuación.

4 Según he analizado en otro trabajo, en prensa $a$ («En los márgenes de la controversia literaria: Góngora vindicado por Angulo y Pulgar»). 
3 i 4. Recogidas i restituidas a su más cierto original con mucho travajo, solicitud i cuidado de muchos, copiosos i buenos papeles i verdaderas noticias de ${ }^{5}$ varios, mui curiosos i entendidos sugetos de Córdova, Granada i otras partes, deudos, amigos i contemporáneos de su autor. I en este volumen comentadas i de su mano escritas por D. Martín de Angulo i Pulgar, natural de la ciudad de Loxa, año del nacimiento de Iesucristo, nuestro redentor. MDCXXXIX

f. $1 \mathrm{v}$ : [Folio en blanco]

f. 2r: [Retrato de Angulo a los 25 años, con firma de Iean de Courbes $^{6}$ y sendas leyendas: Veritas vincit y Tal deve el ombre ser como quiere parecer]

f. 2v: [Folio en blanco]

f. 3r: [Retrato de Góngora por Iean de Courbes]

f. 3v: [Folio en blanco]

f. 4r: [Retratos de varios Monarcas y representación iconográfica de la Fama]

f. 4v: [Folio en blanco]

f. 5r: Romances líricos a reyes. Congratulatoria

f. 6v: O[c]tavas Heroi[cas]

f. 10v: Romances líricos a rey[es]

ff. 11v-12v: [Folios en blanco]

f. 13r: Líricos.

f. 13r: Romance $2 .^{\circ}$ Por D. Filipe 4. N. S. i D. Isabel de Borbón, su esposa

ff. 13v-14r: Romances líricos a rey[es]

ff. 44v-45r: Romances líricos moros

ff. $52 \mathrm{v}-54 \mathrm{v}$ : Romances líricos

ff. 55r-64r: Romances amorosos

f. 64v: [Folio en blanco]

ff. 65r-68r: Romances sacros

ff. $68 \mathrm{r}-84 \mathrm{v}$ : Romances satíricos

f. 85r: Romances burlescos

f. 85r: Romance 1. Fábula de Píramo i Tisbe no acavada

ff. 85r-90v: Romance 2. Fábula de Píramo i Tisbe acabada con toda perfección

ff. 91r-93r: Fábula de Leandro i Ero. Primera parte

f. 93r: Rom. 3. De Ero. Segunda parte

ff. 94v-111r: [Otros romances burlescos Rom.4-Rom.32]

ff. 111r-112r: Rom. 33 [sin redactar, en blanco]

f. 112v: Canciones [satíricas]

f. 112v: Canción. Lira. Ballata o madrigal de una estança

f. 113r: Con qué eficacia el pendolar ministro

5 Duplicado de.

6 Autor, como se sabe, del retrato de Góngora en las Lecciones solemnes de Pellicer y colaborador en el Polifemo de Salcedo Coronel. 
f. 114r: Firmeças de Ysabela. Comedia famosa

f. 114r: Argumento del Acto primero

ff. $114 \mathrm{r}-125 \mathrm{v}$ : [Acto primero]

f. 125v: Argumento del Acto segundo

ff. 125v-138r: [Acto segundo]

f. 138r: Argumento del Acto tercero

f. 138r-153v: [Acto tercero]

ff. $154 \mathrm{r}-154 \mathrm{v}$ : [Folios en blanco]

f. 155r: Canciones heroicas

f. 155r: Canc. prim. A los Católicos Reyes D. Felipe i D. Margarita de Austria, su Esposa, estando la primera vez preñada

ff. 155v-158v: [Otras Canciones heroicas Canción 2-Canc. 5]

f. 159r: Canciones líricas

ff. 159r-159v: Canción 1. ${ }^{a}$ A los Marqueses de Ayamonte i su Armada q[ue] iban por Virreyes a México

ff. 159v-162r: [Otras Canciones líricas Canción 2-Canc. 5]

ff. 162r-162v: Canción sacra. Única

f. 163r: Tercetos heroicos.

ff. 163r-163v: A Luis de Cabrera i a su Primera Parte de la Historia de la R. M. de Filipe Segundo

ff. 163v-165r: Tercetos varios. Quiriendo salir de la Corte D. Luis por el mes de Otubre de 16 [sic]

f. 165v: [Folio en blanco]

ff. 166r-168v: Octavas heroicas [Est. 1-Est. 24]

ff. 169r-169v: [Folios en blanco]

ff. 170r-179r: Panegírico. Oración laudatoria a Prínc[i]pe. Escrita a Don Francisco de Rojas i Sandoval, primer Duq[ue] de Lerma, gran Privado de D. Filipe Tercero, el Piadoso, rey de las Españas [Est. 1-Est. 79]

f. 179r: Octavas heroicas sacras. Por la Capilla q[ue] D. Fernardo [sic] de Rojas i Sandoval labró para Sagrario en la Iglesia Mayor de Toledo donde era Arçobispo i Cardenal... [Oct. 1-Oct. 10]

ff. 179v-182r: [Otras octavas sacras]

f. 182r: Octava fúnebre. Epitafio. En el ataúd de D. Margarita de Austria, reyna de las Españas quando le hiço sus onras la ciudad de Córdova

182v: Fábula de Polifemo i Galatea. Dedicada al excelentísimo Sr[.] Conde de Nie-

bla, ya oy Duque de Medina Sidonia, Don Manuel Alonso Pérez de Guzmán

el Bueno

f. 182v: Dedicatoria [Rima 1-Rima 3]

f. 182v: Argumento de la Rima 1. ${ }^{a}$

f. 183r: Argumento

ff. 183r-190r: [Rima 1-Rima 60]

f. 190v: [Folio en blanco] 
f. 191r: Varias poesías i casi todas las que compuso aquel ilustre, ingeniosíssimo, erudito i doctíssimo varón D. Luis de Góngora, natural de la ciudad de Córdova, racionero de su Santa Iglesia, capellán de las S. C. i R. Magestades de D. Filipe $3 .^{\circ}$ i $4 .^{\circ}$. Recogidas i restituidas a su más cierto original con mucho trabajo, solicitud i cuydado de muchos, copiosos i buenos papeles i verdaderas noticias de varios, muy curiosos i entendidos sugetos de Córdova, Granada i otras partes, deudos, amigos i contemporáneos de su autor. I en este volumen comentadas i de su mano escritas por D. Martín de Angulo i Pulgar, natural de la ciudad de Loxa, año del nacimiento de Iesucristo, nuestro redentor. MDCXXXX o 1640

f. 191v: [Folio en blanco]

f. 192r: [Como en el códice precedente, retrato de Angulo con 25 años por F. Heylan; leyendas: Veritas vincit y Tal deve el ombre ser como quiere parecer]

ff. 192v-193v: [Folios en blanco]

f. 194r: Sonetos heroicos

f. 194r: Soneto I. A N. Peregrino, flamenco de nación, pintor que retrataba a Don Luis

ff. 194r-207r: [Otros sonetos heroicos: 2-58]

f. 207v: Sonetos sacros

f. 207v: Soneto I. Disputa i resuelve quál sea más en Dios i por qué el nacer que el morir. Argumento

f. 207v: [Otros sonetos sacros: 2-8]

f. 210r: Sonetos fúnebres

f. 210r: Soneto I. Consideración de la muerte, i del Infierno, poderosa para librarse de ambas cosas. Argumento

ff. 210r-216v: [Otros sonetos: 2-25]

f. 217r: Sonetos amorosos

f. 217r: Soneto I. Por D. Filipe 3. ${ }^{\circ}$ i D. Margarita de Austria, reyes nuestros i de las dos Españas

ff. 217r-226v: [Otros sonetos: 2-50]

f. 227r: Sonetos satíricos

f. 227r: Soneto $1 .^{\circ}$ A Don Antonio Moscoso, Marqués de Villanueva

ff. 227r-234v: [Otros sonetos satíricos: 2-37]

f. $235 \mathrm{r}$ : Sonetos burlescos

f. 235r: Soneto I. A la ciudad i Corte de Valladolid

ff. 235r-241v: [Otros sonetos burlescos: 2-36]

f. $242 \mathrm{v}$ : Sonetos varios

f. 242v: Soneto I. Por una enfermedad que tuvo D. Luis en Salamanca

ff. 242v-245r: [Otros sonetos varios: 2-13]

f. 245v: [Folio en blanco]

f. 246r: Apéndice a las notas de los sonetos heroicos

ff. 246r-260r: Al soneto 1. ${ }^{\circ}$ Apéndice 
ff. 260v-262v: [Folios en blanco]

ff. 263r-326r: Todas las cartas de D. Luis de Góngora que corresponden a las presentes poesías ${ }^{7}$

ff. 326v-330v: [Folios en blanco]

\section{ANÁLISIS DEL CONTENIDO}

\subsection{NOTAS BIOGRÁFICAS DE GÓNGORA Y CIRCUNSTANCIAS COMPOSITIVAS}

En el manuscrito, las notas de Angulo ofrecen datos más o menos acertados sobre la vida y obra de Góngora, si bien con frecuencia remozados de cierta fantasía creativa, y a menudo con un especial énfasis por el maridaje entre la voz poética y la música; así en f. 19v, «Rom. 12. Compúsolo para cantar en la vigüela i agradó tanto que el mismo Sr. Rey D. Filipe 3, el piadoso, compuso tono a tres voces con notable primor i dulçura [...]», como también el romance «Pregono, pregono / que sale un toro.... ${ }^{8}$ y en f. 201r, en la sección de Sonetos heroicos, el 33, «Un culto Risco, en venas oý süaves», al que sigue una glosa interpretativa del poema: «A Don Diego Mardones, Obispo de Córdova dedicándole unos villancicos del santíssimo Sacramento, compuestos por D. Luis las letras i la música por Juan Risco, maestro de capilla en su iglesia, donde se cantaron, año 1617. Están en la pla[na]».

Otras circunstancias compositivas de la obra poética de Góngora que interesaron a Angulo, en las fronteras entre la realidad y la ficción, y con no escasas dosis de voluntad estética, se encuentran en ff. 24v-25r («Rom. 29. A D. Antonio Ponce de León i Chacón, señor de la Villa de Polvoranca, amigo íntimo de D. [L]uis [...]. No acabó D. [L]uis este dulce y grave romance, ni hiço dél más que estas coplas».), al igual que en la sección de Romances burlescos, f. 99r, esto es el titulado

7 En una alternancia sistemática de los textos con folios en blancos.

8 Véase: Luis de Góngora (1998 IV: 385-389), n. ${ }^{\circ}$ 292, sección Romances atribuidos; cfr.: f. 25v, Rom. 21: «Este romance compuso D. [L]uis para cantar en guitarra, i con el transcurso del tiempo, q[ue] todo lo olvida, se perdió i se a hallado con mucha dificultad a retaços i falto. Fue muy celebrado de los q[ue] entendieron la tácita materia que contiene q[ue] no e podido alcançar verdadera. Cada uno le dé el sentido que le pareciere mejor, que el mío es este: A un cavallero se le ofreció ausentarse de la dama que servía i la dejava con peligro de que le olvidase admitiendo a otro; persuádele que no se ausente i finge una lidia de toros, i q[ue] es uno el olvido, en la plaça de la ausencia; i q[ue] como los toros matan con cuernos, el Amor permite ponérselos al ausente, olvidándole su dama; i concluye aconsejándole con q[ue] pues ya no le matan celos i a goçado de la dama, la deje, antes que ella a él le dé con el olvido. Adviértele que lo quiere hacer i q[ue] el mayor alano i de más pena que le puede arrojar a la oreja del toro deste olvido desta dama es dejarla; i ruega que no sea exemplo de daño a otros no hacerlo; i dejándose atropellar deste toro i del amor desta dama». 
«Temo tanto los serenos» ${ }^{9}$. No faltan tampoco a este respecto los Romances amorosos, en f. 57r («Rom. 4. Que no acavó o no se halla más»; «Los cristales de Genil» y «Rom. 5. Que no acavó»; «Al pie de un árbol robusto») y f. 57v («Rom. 6. Que no acavó DL.»; «O tú, que pendiente al ombro i»); Sonetos satíricos, f. 228r («Soneto 8. A N. Vallejo, autor de comediantes») ${ }^{10}$ y f. 228v («Soneto 9. A N. Baldés, autor cómico») ${ }^{11}$. En la misma sección, se hallan otras noticias sobre teatro, autores y comediantes, con una notable presencia femenina y algo de intrahistoria, en tiempos de Góngora: f. 228v, «Soneto 10. A ${ }^{12}$ Isavel de la Paz. Dama fue cómica»; f. 228v, «Soneto 11. A la misma Isavel de la Paz»; f. 229r, «Soneto 12. A María de Vergara. Fue comedianta»; y f. 229v, «Soneto 14. A Josefa Baca, autora hermosa de comedias i muger de N. Morales».

Por otra parte, especial atención pone Angulo en sus notas al posicionamiento y truncada carrera de Góngora en la corte, con ambiciosa querencia y desencantado aborrecimiento de fondo. Así se trasluce en la sección de Tercetos varios, f. 163v («Queriendo salir de la Corte D. Luis por el mes de otubre de $16[\mathrm{sic}]^{13}$. Argumento 1 , número $1 »)^{14}$, con realce estético creativo en el estado anímico de desengaño, soledad y resentimiento del poeta por su frustrada aspiración profesional, en f. 195r, Sonetos heroicos («Soneto 6, al Apénd[ice] 5, pla[na] 108») ${ }^{15}$

9 «Rom. 10. A D. Pedro de Cárdenas i Angulo, cavallero de la Orden de S[an]tiago. Enbió a combidar a D. Luis para jugar a los naipes. Discúlpase con que es de noche i nótale de impaciente quando pierde a ellos».

10 «En una comedia del Antecristo (compuesta por D. Juan de Alarcón), en una de las tramoyas avía de volar i no se atrevió, i assí voló por él Luisa de Robles, viçarra i hermosa. [Espacio en blanco.] Aprueva D. Luis el averse escusado de volar motejándole de cornudo voluntario; aconséjale q[ue] deje el volar para los ángeles q[ue] tienen alas i no cuernos como él, i como se escusó, no le vieron volar, quedando con tal peso en la caveça».

11 «Lamentásele su muger, Gerónima de Burgos, de q[ue] N. de Gante (otro autor sería) se le aventajase en ser sufrido i en el caudal porque descaecía el suyo i su estimación. Quéjase de [que] no tiene ya la q[ue] antes en sus comedias Lope de Vega, i q[ue] N. Alcante, alguacil de Corte, les chupaba el dinero, i ella avía engordado tanto q[ue] ya no era celebrada, i assí le aconseja q[ue] se tornen a ser ermitaños como Baltasara (dama de comedias seria), mas él respondió: "pues ya no estáis para el teatro, tomen un bodegón donde, usando de todo, ganéis para ambos". No [corrijo: $\mathrm{Ne}$ ] e podido entender mejor el terceto 1, q[ue] parece, i no es, [supra lineam: i no es] errado. Save el cielo, Baldés, si me a pesado».

12 Angulo corrige Por en $A$.

13 Espacio en blanco.

14 «Viendo q[ue] no le aprovechava o no hallava favor en los Señores para lo q[ue] pretendía i hallándose muy pobre (desgracia propia suya), maldice a los q[ue] se fían dellos i, gastándose ambiciosos, quedan pobres».

15 «Desengañado ya D. Luis de no conseguir una merced de una pensión a [supra lineam: a] que pretendía en Córdova, con alegoría de cinco religiones, da a entender cómo está despedido de la Merced, por causa de su fortuna; que se irá a la Compañía de sus deudos, forçado de su pobreça; 
o f. 210r, en Sonetos fúnebres ${ }^{16}$; y finalmente en ff. 216r-216v, en la misma sección, como se demuestra en el «Soneto 25. Habla por sí mismo con todos los hombres. Compúsole año 1624, a los 63 años de su edad ya desengañada. [...] En este occidental, en este, o Licio».

Como se ve, el tono de desengaño y desencanto como denominador común de este ciclo de poemas lo hace dialogar creativamente Angulo con lo que él considera un pretendido anhelo de trascendencia por parte de Góngora, identificable al parecer en su poesía «a lo divino», que el comentarista reivindica en f. $207 \mathrm{v}$, sección de Sonetos sacros, concluyendo con el apunte: «Algunos dixeron que D. Luis no aplicó su alto espíritu a la poesía sacra...». No obstante, dicho juicio valorativo sobre tal «contrafactum a lo divino» volverá a reaparecer en los Sonetos amorosos, en concreto en el 7 («A solo pelear con dos barriles»), f. 228r: «No le inspiró la musa, como otras veces, en lo espiritual i trocó la glosa a los ministriles i desta ocasión, $\mathrm{o}^{17}$ de otras, se originó sin duda la injusta fama q[ue] a D. Luis se le atribuyó de que no levantó su espíritu a lo sacro, mas es falsa [...]».

\subsection{GÓNGORA ENTRE LA REALIDAD Y LA FICCIÓN:}

VOZ DE LA ENUNCIACIÓN POÉTICA Y SERMOCINATIO

En consonancia con lo señalado en el apartado precedente, Angulo da claras muestras de su predilección por representar a Góngora como personaje actante en el marco de la ficción, atribuyéndole al autor la responsabilidad, a efectos de veracidad y verismo, del mensaje, sentimientos y emociones transmitidos por la voz de la enunciación poética. Así sucede, como una constante preñada de pretendida verosimilitud, a modo de sermocinatio y en virtud de su imaginación creativa, en la sección de Romances burlescos, f. 106r («En todos los rom[ances] que se siguen habla D. Luis por sí mismo. Rom. 24. La ociosidad i exercicios en $\mathrm{q}[\mathrm{ue}]$ vivía quieto hará $\mathrm{q}[\mathrm{ue}]$ le hirió el Amor. Dice sus propiedades i pídele perdón. Agora, q[ue] estoy de espacio...»), hasta el punto de proponer, en el diseño

que si la culpa fue el ser del Carmen, el ser Poeta, sobre averle hecho merced por ello de un ávito, se volverá a su patria contento, ya q[ue] vuelve descalço i pobre; i aunque es Capellán del maior Rei del Mundo, será Fraile Mínimo de la Vitoria, i sugeto ya a su adversa Fortuna, hará voto solene de vida Quaresmal, pues su caudal no alcança para más. De la Merced, [tinta en rojo, marcando la llamada de la nota] señores, despedido, [...]».

16 «Donde muestra D. Luis la grandeça de su espíritu i junta exemplos grandes para desengaño desta vida $\mathrm{i}$ útiles moralidades para alcançar dichosa quietud en la otra i para lo poético nuevas i galantes frases, gravedad en las voces, atención en la narración i en lo doctrinado, proporcionándolo todo con la materia fúnebre i con los sugetos de quien i con quien habla en ella». Soneto 1. Consideración de la muerte i del infierno, poderosa para librarse de ambas cosas.

En vez de $u$ en el manuscrito. 
general de su proyecto entre la ciencia editorial y la aspiración creativa, una suerte de cancionero amoroso con notas de ética y etología moral por añadidura, que tiene como eje vertebrador o referente axial a las damas, como en f. 106v («Rom. 25. Prosigue el suceso q[ue] tuvo con esta dama, o sea con otra; no está caval ni fiel. Antes $\mathrm{q}[\mathrm{ue}]$ el sueño me vença...»), incluso con problemas de atribución autorial en $\mathrm{f} .107 \mathrm{r}^{18}$.

\subsection{LA IMAGEN POÉTICA DE GÓNGORA ENTRE EL REFLEJO, EL VISLUMBRE Y EL FULGOR: LA RETÓRICA VISUAL de ANGUlo}

Otra de las directrices esenciales que implementa Angulo al servicio de su personal proyecto editorial de canonización de Góngora, y de él mismo como editor y creador, viene dada por la forja y creación de la imagen poética de su laudandus, por lo general entre la realidad y la ficción a partir de una pretendida construcción biográfica del autor cordobés, como se ha demostrado. Lo comprobamos en el f. 194r, sección de Sonetos heroicos, en concreto el Soneto 1 («A N. Peregrino, flamenco de nación, pintor que retrataba a Don Luis») $)^{19}$, con escolios en los que facilita la identificación de sus modelos principales, esto es, Horacio y Virgilio, esclareciendo al tiempo el significado integral del poema, sus figuras retóricas, etc., para concluir con el siguiente apunte en una nueva confluencia entre vida y literatura: «En los cinco sonetos que se siguen manifiesta Don Luis su adversa fortuna, trabajo que casi siempre padecen hombres de tan grande ingenio».

Ahora bien, Angulo no se limita al mero bosquejo prosopográfico de Góngora, con más o menos visos de verosimilitud, sino que amplía su espectro de actuación en virtud de otros retratos y galerías afines. Algunos ejemplos representativos sobre este particular se hallan en la sección de Sonetos heroicos, f. 206v, Soneto 57 (“"O tú, qualquiera que entras, peregrino". A una galería del señor cardenal don Fernando Niño de Guevara, arçobispo de Sevilla»), con alusiones a la «hermosa galería, clara por las vidrieras q[ue] la circundan, i más clara por la divina pintura que en sí contiene [...]», el retrato de este cardenal por el Greco, en ff. $215 \mathrm{v}-216 \mathrm{r}$,

18 Rom. 26. «Aunq [ue] no es indigno el argumento deste r[omanc]e del genio de D. L., todavía no parece suyo en las coplas; i la 21, qualquier poeta de Córdova pudo decir lo mismo. El en fin es reprehender el uso de nombres moros para disimular los poetas los de sugetos q[ue] cantan; adviérteles q[ue] pueden i deven usar de los nuestros, de los de pastores, $\mathrm{i}$ franceses. A mis señores poetas...». Véase: Luis de Góngora (1998 III: 234-240), n. ${ }^{\circ}$ 135; sección De atribución menos fundada.

19 «Argumento. Quanto el lienço en que me retratas debe más vida a tu pincel, tanto temo verlo hecho ceniças, pues llega a ser émulo del cuerpo a quien Prometeo dio alma de fuego; pero aunque no se la puedas dar tan verdadera, prosigue, belga insigne, mi retrato, que a de vivir muchos años, pues [-es supra lineam] el roble los vive, aunque insensible, i el hombre, aunq[ue] oye i ve, vive menos $[\ldots] \gg$. 
Sonetos fúnebres («Soneto 23. Epitafio al sepulcro de Domínico Greco, gran pintor i escultor») $)^{20}$, Sonetos heroicos, f. 200r, Soneto 38 («Al retrato de D. Juan de Acuña, Presidente de Castilla por Filipe $3 .^{\circ}$ Fue Marqués de Valle»), con las características marcas deícticas («Este que...»), tanto en el íncipit del poema como en la glosa argumental, en la que se insiste en «el pincel que lo retrató» y «el tiempo sea buril que le grave en bronce $\mathrm{i}$ haga inmortal la memoria de su nombre», con ecos del aere perennius horaciano.

Como se ve, sobresale por tanto la sensibilidad estética de Angulo por determinadas técnicas pictóricas y de retórica visual asociadas al retrato, el valiente pincel y el claroscuro mediante contraste; así en Sonetos heroicos, f. 199r, una vez más a propósito del Marqués de Ayamonte ${ }^{21}$, f. 200v, Soneto 30 («Sacro pastor de pueblos, que en florida»), donde se dice que «[...] el mismo Apolo cante la curiosidad de su oratorio, adornado de santos mártires en escogida pintura en marcos dorados, tan curiosamente dispuestos i de tan valiente pincel, $\mathrm{q}$ [ue], aunq[ue] lo eran, parecían cuerpos vivos i ángeles mudos, cielo suyo i vestuario de sus almas, la sala en que estaban», en f. 199v, Soneto 27, dedicado al Conde de Villamediana con alusiones a la «valiente pintura», en diálogo con el «pincel valiente» del v. 5 , e incluso con variaciones sobre el «escultor valiente» en f. 217v, y en Sonetos amorosos, Soneto 4 («Qual, del Ganges marfil, o qual de Paro»). Del mismo modo, no están ausentes tampoco otros notorios aspectos circunscritos a la retórica visual y potenciados además en el Polifemo ${ }^{22}$, como en f. 195v, Sonetos heroicos, Soneto 8, «Teatro espacioso, su rivera», en el escolio

20 «Este sepulcro de alavastro curiosamente labrado es del más valiente pintor q[ue] tuvo el mundo su nombre, digno aun de mayor memoria q[ue] le puede dar la Fama [sustitución de minúscula por mayúscula mediante una corrección autógrafa]. Está esculpido en este mármol. Venéralo, ô peregrino, i pasa adelante. En él yace un pintor por excelencia, el griego. Con su muerte eredó la Naturaleza el Arte q[ue] la perficiona; el Arte q[ue] le adelanta sus primores, el Arco del Cielo colores vistosamente mezcladas, luces el Sol i Morfeo sombras; urna que contiene hombre tan eminente ablándese con sentimientos i beba lágrimas de los q[ue] sobre ella lloran su muerte; i el humo q[ue] exalan las corteças del cinamomo, que sobre ella queman (assí lo deven) los que la visitan».

21 Soneto 24. «Al Marqués [de Ayamonte] mismo, caminando de noche i porq[ue] le mostró un retrato de la marq[ues]a a D. Luis. Disc[reto], novilíssimo $s[e n ̃ o] r$, claro en sangre i entendimiento, i claro i noble infinitas veces por la clara luz q[ue] liveralmente me mostráis de los dos ojos semejantes a dos soles, que del hermoso cielo del rostro de la marquesa, traéis retratados en vuestro ilustre pecho, de un valiente pincel que los copió, atrevimiento, que aun fuera pequeño castigo del morir abrasando dellos, que pintor fue águila q[ue] pudo mirar a tanta luz i hermosura, i copiaros los rayos del sol de su divina velleza [trazado el vocablo sobre una corrección autógrafa], mirándola en este retrato, camináis de noche, pero es luciente i clara, que no puede ser escura, con los dos soles que en él lleváis en sus dos vellos ojos».

22 Según analizo en un artículo en prensa $b$ : «Martín de Angulo lector de Góngora (con notas inéditas al Polifemo)». 
«THEATRO $»^{23}$, o en f. 220v, Sonetos amorosos («Soneto 20. Píntale su rigor, en ella misma, a esta o a otra dama») ${ }^{24}$.

\subsection{Fronteras ENTRE LOS GÉNEROS POÉTICOS: HIBRIDACIÓN}

Además del maridaje ora la pluma, ora el pincel identificable en el códice, en lo que hace a la caracterización genérica empleada por Góngora en su obra poética, Angulo se muestra especialmente atento al mestizaje o hibridación genérica; por ejemplo tiene lugar en la sección de Canciones heroicas, al hilo de la canción y la silva, en f. 155v («Canc. 3. ${ }^{a}$ En la creación de cardenal de la Sta. Iglesia de Roma del eminente Sr. D. Enrique de Guzmán i Haro, hijo segundo del Marqués del Carpio. Estancia» $)^{25}$, o a propósito de las fronteras e intersección de códigos genológicos entre madrigal, canción y silva en Canciones líricas, f. 159v («Madrigal Canci. 2 o Silva. A don Fran[cis]co Manuel de Zúñiga, marqués de Ayamonte»), con alguna marca retórica de écfrasis ( «Pinta») como arranque ${ }^{26}$. También destaca a este respecto, sobre el Marqués de Ayamonte y el ciclo ayamontino, el no siempre verosímil mensaje identificable en la voz de la enunciación poética que refleja, al decir de Angulo, la experiencia vital del escritor en los Sonetos heroicos, en concreto en el «Soneto 17. A D. Francisco Manuel de Guzmán, marqués de Ayamonte, llegando D. Luis a Lepe» ${ }^{27}$, sin olvidar tampoco el Soneto 18, «Cisnes de

23 «[...] Los poetas usan variamente destos nombres [teatro, circo, anfiteatro i espectáculo] pintando en un lugar lo q[ue] se exercitava en el otro i al contrario, assí como en el teatro lo que se exercitava en el amphiteatro».

24 «Restituid (dice) las colores de vuestra velleça al oro, a la nieve, a las perlas i coral, i los ojos al cielo i a Dios la gracia i discreción, i veréis q[ue] lo que os queda vuestro es solo ingratitud i crueldad. Dejad las hebras de oro ensortijado».

25 «Porq[ue] las tres estancias desta canción (a quien otros llaman silva) son largas i contienen cosas varias i varían sus consonantes, i la quantidad de sus versos para mayor claridad las divido en fragmentos i hago argumento a cada uno, fácil será al letor juntarlos después, i lo mismo en las $\mathrm{q}[\mathrm{ue}]$ se a de hacer otro tanto». Se trata, en efecto, de la conocida canción «Generoso mancebo, / purpúreo en la edad, más q[ue] en el vestido».

26 «Pinta un prado en una casa de placer junto a Guadiana; atribúyele al Marqués el nombre de Apolo; i q[ue] porque desta recreación deja el Parnaso de su palacio i viene con sus damas, hácelas Musas, compáralas a un enjambre de avejas i dice q[ue] vien[en] tañendo i cantando. Por este culto bien nacido prado».

27 No obstante, Angulo realiza su peculiar paráfrasis de estos versos enfatizando para ello el empleo verbal de la primera persona en aras de conseguir, con mayor eficacia comunicativa, dicho efecto estético de verosimilitud: «Triste i lleno de cuidados, pobre i descaminado, llegué a tu villa (por donde el río Guadiana entra en el mar Mediterráneo), donde un edificio real i hermoso, que vide con el escudo de tus armas, me enseñó que era tu palacio, templo donde a tu esposa i hija veneran tus vasallos; i si yo, por ser pobre, no les ofrecí don alguno, les manifesté mi voluntad [...]. A los campos de Lepe, a las arenas $[\ldots]$... 
Guadiana a sus riveras» e igualmente los siguientes del ciclo ayamontino $(19,20$, $21,22,23,24,25)$, bien estudiados por Jesús Ponce (2013), aquí con nuevos datos para el análisis.

Más interés reviste en cambio la marcada oposición genérica que establece Angulo entre la canción real o lírica versus canción heroica, con la intención ya de paso de sacar a la luz algunos errores o imprecisiones que detecta en las ediciones de Góngora. Sucede en el f. 160v con motivo de la canción «En roscas de cristal, serpiente breve ${ }^{28}$, si bien se identifican otras críticas sui generis a estos libros impresos $^{29}$; así, referido a Gonzalo de Hoces, en la nota Eritreos (Apéndice, f. 252r): «Eritreos. Del mar Bermejo. Otros leen (con la última edición de las obras de D. L. por don G[onzal]o de Hoces) rubicundos, mas no es voz erudita, como eritreos. I para explicarla digo con Plinio (i otros), lib. 6, c. 23, q[ue] es griega i sinifica lo mismo q[ue] en latín rubrum i en nuestro idioma, bermejo, purpúreo o rojo [...]», con implicaciones en lo que atañe a una espinosa atribución autorial, que será una tónica dominante en otros pasajes del códice; por ejemplo en f. 37r, «Rom. 34. [...] Una bella caçadora... [...] Dicen q[ue] D. L. negó el ser suyo este rom[anc]e», f. 41r («Todo lo demás deste romance no es de D. Luis». Rom. 38 «Entre los sueltos cavallos») y sobre todo en la sección de Sonetos heroicos, f. 208r, Soneto 3 («Pío lector, yo soy un hombre rudo»), de manera que Angulo concluye con un apunte más o menos aclaratorio proporcionado por un informante: «Algunos dijeron que no fue de D. Luis este soneto, pero el do[cto]r Luis de Babia, Capellán real de Granada, me lo dio i dijo que el mismo D. Luis se lo embió por suyo, i escrito de su mano, i assí me lo mostró»».

\subsection{LABOR DE ANGULO COMO EDITOR, COMENTARISTA E INTÉRPRETE: HACIA EL GÉNERO DEL CENTÓN}

Pero sin duda la labor más meritoria de Angulo como editor con comento y glosa en su códice autógrafo se traduce en un notable esfuerzo, dentro de su a veces exigua erudición de fuste ensayístico, por la aclaración de realia, referencias históricas, mitológicas, bíblicas..., tratando de desentrañar en virtud de interpretaciones simbólicas el «secreto» artificio de su modelo y auctoritas; eso sí, en la mayoría de las ocasiones, se limita más bien a realizar un juicio estético valorativo muy

\footnotetext{
28 Canc. 4. «Esta real canción, aunq[ue] de tan altos i hinchados versos, i aunq[ue] la dan por heroica las dos muy erradas ediciones de las desgraciadas [enmienda: desgradiadas] poesías de Don Luis (por q[ue] imiten a su dueño) verdaderamente es lírica. Por ser la más dificultosa de quantas compuso, le di el último lugar en las de su especie. En los argumentos está incluida la construcción de las cláusulas o períodos más gravemente colocados i con mayor alteça de estilo».

29 Como he analizado en otro trabajo: «En los márgenes de la controversia literaria...» (Escobar en prensa $a$ ).
} 
personal y no siempre certero de la poesía de Góngora desde su privilegiada atalaya de entusiasta comentarista o laudator. Para ello suele conectar poemas bien dispares del auctor cordobés mediante alusiones temáticas a modo de centón, cierto halo de crítica literaria y en diálogo a su vez con una tabla de varia erudición a modo de apéndice. A este respecto, pasaré, en primer lugar, a desentrañar las principales referencias tanto intratextuales como intertextuales, con palpable trasfondo biográfico, de las que se valió Angulo como editor, comentarista e intérprete de Góngora en este códice. No obstante, dicho andamiaje técnico le permitió ir forjando su peculiar concepto de centón como género creativo que culminaría en un nuevo tributo dedicado al autor cordobés: la Égloga fúnebre.

\subsubsection{Referencias intratextuales}

Como se ha indicado, Angulo vincula y hace dialogar entre sí los poemas de Góngora, a modo de claves hermenéuticas internas en la dispositio integral del códice, con el objeto de facilitar no solo la lectura, remozada una vez más de pátina biográfica, sino también la asociación de claves temáticas de su modelo. Lo demuestran los siguientes ejemplos, esto es, en f. 196v, Sonetos heroicos. Soneto 12 , «Florido en años, en prudencia cano», en cuya nota se remite al Polifemo («El vello flores de su primavera, i por la poca edad de Acis en el Polif., r. 32»), e igualmente en la nota Redil de su Apéndice, f. 251v, citando de nuevo conocidos versos de este poema mayor de Góngora ${ }^{30}$, técnica a la que Angulo volverá a recurrir por cierto a propósito de la «Rim. 58. Violos huir Polif[em]o (porq[ue] era de tanta vista $\mathrm{q}[\mathrm{ue}]$ alcançava con ella a ver las adargas de los africanos); previno qué tirarles, dando un grande i celoso grito; hácelos semejante al trueno, cuyo ruido previene $\mathrm{q}[\mathrm{ue}]$ quiere salir el rayo. [...]». Incluso en un escolio marginal, como una referencia intratextual complementaria ubicada en el lado izquierdo inferior de la octava, puede leerse en esta misma dirección compositiva por parte de Angulo: «R. 41,47 y 49 toda».

Sin embargo, el comentarista no se limitó únicamente al Polifemo sino que llega a aplicar este procedimiento técnico en otras secciones de su manuscrito, es decir, como si estuviese tejiendo en el seno mismo de su codex excerptorius un centón temático gongorino, o sea reflejo de su officina, modus operandi y carpintería creativa implementada en su Égloga fúnebre. Principalmente se demuestra

30 Redil. «Es un cercado q[ue] se hace de redes donde los pastores guardan, amparan i recogen su ganado. Díxolo con la gala que suele D. L. en la 3 rima del Polif[em]o i por su cueva, donde se recogía él i sus ovejas: $i$ redil espacioso donde encierra. Cuanto las cumbres ásperas cabrío, de los montes esconde». 
en Sonetos heroicos, f. 199v, en relación con la Fábula de Píramo y Tisbe y a propósito del Soneto $26^{31}$, pero también en f. $219 \mathrm{v}$, Sonetos amorosos («Soneto 15. Habla con la misma casería donde estava esta dama») ${ }^{32}$ y otros casos identificables en la sección de Sonetos sacros; por ejemplo en f. 209r, Soneto $7^{33}$, de suerte que el editor cierra su comentario con una nota aclaratoria sobre los lazos no fáciles entre Góngora y Juan de Pineda, con censura de por medio ${ }^{34}$. Es más, como correspondencia interna en el manuscrito, en la sección de Sonetos fúnebres, encontramos el 10 («Esta que admiras fábrica, esta prima»), con apuntes aclaratorios intratextuales como los siguientes: «Todo lo que aquí está escrito tocante al $\mathrm{P}$ [adre] Pineda es del soneto 7 sacro, pla[na] 31 i no deste menos»; y «Lo del soneto "Esta capilla q[ue] el ilustre" que me dixo Juan Villegas (a quien hiço D. L. el son. heroi. 20, pla. 3) q[ue] no es de nuestro poeta». De hecho, este informante es a quien dedicó Góngora, como recuerda Angulo, el soneto, de 1615, «En villa humilde sí, no en vida ociosa (A Juan de Villegas, alcalde mayor de Luque, por don Egas Venegas, señor de aquella villa)».

Por último, el voluntarioso editor aprovecha este poliédrico diálogo entre los textos de Góngora, a modo de mosaico reticular, con el fin de ponerlos en relación con otras empresas suyas dedicadas al poeta cordobés. Es el caso, como se ha apuntado, de su Égloga fúnebre, redactada a modo de centón en la tradición de Ausonio y otros autores de la tradición clásica, a propósito de Lícidas que aparece en su fuente, es decir, la canción «Perdona al remo, Lícidas, perdona». Por ello, en f. 19r puede leerse, bajo el empleo del nombre «parlante» como máscara de aliento biográfico o impostación identitaria referida al Conde de Niebla, «Rom. 11. Sean propios amores los q[ue] canta en este romance, de tan suave número i estilo,

31 «A Don Cristóval de Mora, primer marqués de Castel Rodrigo. Estirpe de Moral dichoso, cuias ramas en lugar de moras dan por fruto a las armas de tu antigua Casa de las Quinas, del rey de Portugal, teñidas, no con sangre vertida por des[h]onestos amores, como la de Píramo i Tisbe [...]».

32 «[...] i vos, [dirigiéndose a la Pared] secreto resquicio por donde puedo verla, sedme más favorable $\mathrm{q}[\mathrm{ue}]$ aquel por donde se vían Píramo i Tisbe porque mis amores no acaven sin goçarse como los suyos».

33 «En una justa poética en la beatificación de S. Ignacio de Loyola en Sevilla, año 16[sic; espacio en blanco], a [espacio en blanco] del mes de março. Juez fue el P[adre] Juan de Pineda y no lo premió. Véase el Soneto 20 satí[ric]o, pla[na] 74 [...]. Todo lo q[ue] se dice del P[adre] Juan de Pineda en el soneto fúnebre, pla[na] 38, es deste i no de aquel, menos lo del soneto "Esta capilla q[ue] el ilustre"».

34 «Con la memoria deste célebre soneto pudiera (i fuera justo) borrar de la suia el P[adre] Juan de Pineda la enemistad que a tenido a D. Luis, pues aun después de muerto, la muestra contra sus obras prohiviendo, como dueño del expurgatorio, algunos de los libros que dellas se an [enm.: sea an] impreso; i si dejó alguno, fue por su gran mecenas. El origen desta enemistad se hallará en el Soneto [blanco] fúnebre [blanco], pla[na] [blanco]». De hecho, este Soneto 20 se incluye en el f. $230 \mathrm{v}$. 
como los dos precedentes, o sean del Conde de Nievla devajo del nombre de Lícidas pescador, enamorado de Clori, que no le oía sus quejas, i por encarecer el afecto del amante pues aún de noche busca la soledad para cantarlas i el sosiego de la noche...», con resonancias del motivo del vaticinio ex eventu y Napea de la Égloga fúnebre y claras deudas para con el Panegírico al Duque de Lerma (est. 12 ss., f. 171r ${ }^{35}$. De hecho, Angulo muestra, como otra constante estética respecto a su labor de taracea gongorina en el manuscrito, su interés por la caracterización genérica del centón, esto es, vinculada a las posibilidades creativas que le ofrecen las claves temáticas internas en la obra de su modelo; por ejemplo, en el apéndice, ff. 236v-237r, en concreto en la entrada Cano: «Don García de Barrionuevo, Marqués de Cusano, refiere de Diodoro Sículo, in Proe[mio] Bibliot[eca], en el eruditísimo panegírico en centón q[ue] compuso en gracia i alavança del Conde mismo, a quien D. L. cantó este soneto» ${ }^{36}$.

\subsubsection{Referencias intertextuales (e interpersonales)}

Como otra directriz técnica y compositiva de su proyecto editorial, Angulo suele entablar un continuo diálogo intertextual, a modo también de centón conceptual y temático, entre la obra de Góngora y la de otros coetáneos suyos, de indiscutible notoriedad para el canon áureo y la historiografía literaria. Entre ellos destaca en un lugar preeminente, claro está, el Conde de Villamediana y La Gloria de Niquea, así en f. 16v («Roman. 8. Sacose de la comedia de la Gloria de Niquea porq[ue] la compuso D. Luis como las otavas de su introducción») y f. $166 \mathrm{r}^{37}$, hasta el punto de que la transcripción de las octavas tiene como broche final una anotación aclaratoria y complementaria de Angulo sobre esta labor de cooperación literaria entre varios autores ${ }^{38}$. Es más, siguiendo este proceder compositivo con resonancias

35 Que analizo con detenimiento en la edición que estoy preparando del poema.

36 Precisa además Angulo la referencia textual: «Apéndice al Son. 12, pla[na] 6».

37 Octavas heroicas. «Para preámbulo a la loa de la comedia q[ue] salió entonces i se imprimió después, por D. Juan de Tasis, Conde de Villamediana (aunq[ue] ay versos de otros poetas), compuso D. Luis estas otavas i las representaron las Sas. D. Margarita de Távora, q[ue] hiço la corriente del Tajo i D. Francisca de Távora, el mes de abril, i D. Antonia de Acuña a la edad [sic]. Dedicose la comedia al día natal en q[ue] cumplió el Rey, nuestro Sr., 17 años, a 8 del mes de abril de 1622. Representó en ella la Reyna la Infanta i sus damas. Intitúlase La Gloria de Niquea i descripción de Aranjuez. Todos los aparatos i apariencias della, q[ue] fueron notables i grandiosos se hicieron a espensas del Conde; i salió la Corriente en un car[r]o triunfal lleno de grandeça i adornado de hermosa riqueza».

38 «Otro romance hiço también D. Luis en esta comedia; hallárase en la plana: "Baquero, escúchame un rato". I de lo uno i lo otro fue testigo de vista el doctor Salvador de Chavarría, capellán q[ue] oy es en la Capilla Real de Granada, 25 de agosto, anno 1634 Nativis Christi Domini»; esto es, uno de los pocos informantes que Angulo menciona de forma explícita en su códice. 
biográficas, Angulo entabla también otras conexiones textuales, a modo de ataujía poética, entre Góngora y Villamediana en f. $31 \mathrm{r}^{39}$, pero especialmente en el Panegírico al Duque de Lerma (est. 76, f. 180v) ${ }^{40}$, con alguna reflexión de por medio sobre la oscuridad como categoría estética, según se comprueba en f. 212v, en la sección de Sonetos fúnebres ${ }^{41}$, en la que no falta uno de sus principales y escasos informantes mencionados, o sea, Juan de Villegas Cevallos (f. 213r): «Este soneto habla en el $1 .{ }^{\circ}$ terceto de la muerte del Conde de Lemos. Díjomelo Juan de Villegas Cevallos [...]»; e igualmente en la sección Sonetos heroicos, f. 194r, Soneto 2, argumento; f. 199v, Soneto 27, dedicado al Conde; y f. 200r, Soneto 28, «Al insigne poema de la Fábula de Faetón que el mismo Conde [de Villamediana] compuso en otavas».

Pues bien, al igual que en el caso del Conde de Villamediana, Angulo se propuso evocar, siempre al servicio del damasquinado intertextual integrado en su codex, otros autores áureos señeros que siguieron de algún modo la alargada estela de Góngora, esto es, como otro mecanismo literario de construcción biográfica, de la talla de Paravicino en Sonetos heroicos, f. 199v, Soneto 35 («Al que de la conciencia es, del Tercero»), Pedro Soto de Rojas y su Desengaño de amor en rimas, autor de inspiración gongorina, especialmente su fábula Los rayos de Faetón, recordado en Sonetos heroicos, f. 205r, Soneto 50 («Poco después que su cristal dilata»), el Conde de Salinas en Sonetos heroicos, f. 206v, Soneto 56 («De ríos soi el Duero acompañado»), habida cuenta de que este prócer resulta ser el dedicatario del poema ${ }^{42}$, y Tamayo de Vargas, en Sonetos heroicos, f. 203r, Soneto 42 («Tú, cuyo lustre entre una i otra almena»), aquí en calidad de comentarista de Garcilaso de la $\mathrm{Vega}^{43}$, ponderado como un clásico con comento y glosa en lengua castellana pero también inspirador de reescrituras, palimpsestos y centones en el Siglo de Oro ${ }^{44}$.

39 Rom. 29. «Por el Conde de Villamediana. Galanteava de secreto una dama de palacio i, saliendo el Conde a torear, le arrojó disimuladamente unas flores esta dama i recogerlas él dio motivo para descubrirse sus amores; sintiéronlo ambos; retírase ella, él la solicita i busca en vano; viola un día, mas fue a tiempo q[ue] le hiço un desdén i no le habló. Minguilla, la siempre bella».

40 Est. 76. «Fue nombrado para esta embajada D. Juan de Tasis i Acuña, primer conde de Villamediana, q[ue], ya con ruegos, ya con traças, consiguió la paz i assí a él se la deve España. El Tasis fue de Acuña esclarecido. Ya de Villamediana onor primero».

41 Soneto 11. «A las fatales muertes de D. Juan de Tasis, conde de Villamediana i D. Rodrigo Calderón, marqués de Siete Iglesias i gran privado del Duque de Lerma. La dificultad deste soneto obliga para su mayor inteligencia a construir los quartetos i a dividir el argumento en párrafos, i entiendo que $\mathrm{D}$. Luis lo escureció tanto, con particular cuidado, por la gravedad de los sucesos que en él comprehendió».

42 «A una casa de campo de D. [espacio en blanco] de Silva, Conde de Salinas, que está junto a Duero».

43 «A D. Tomás Tamayo de Vargas, natural de la ciudad de Toledo, que comentaba las obras de Garcilaso de la Vega».

44 Lo analizo en el estudio y edición de la Égloga fúnebre. 
Finalmente, en armonía con tal mención a Garcilaso, Angulo atiende a las implicaciones temáticas, simbólicas y culturales de los textos de Góngora respecto a otros distinguidos autores del XVI, e incluso de entre siglos, con el acopio de datos relativos a la vida sociocultural en Córdoba, como ciudad natal del poeta y a modo de laus urbis natalis. Lo comprobamos, en virtud de apuntes cercanos a la historia de las mentalidades, «ideas» o de las representaciones, con santa Teresa de Jesús en la sección de Romances sacros, f. 66r, con motivo del romance «De la semilla, caída» ${ }^{45}$, reforzando así Angulo su imagen de Góngora como poeta «a lo divino» y, sobre todo, con Juan Rufo y su Austríada, como proyección de la faceta «heroica» o «sublime» del autor de las Soledades, en Sonetos heroicos, f. 204r, Soneto 47, “"Cantásteis, Rufo, tan heroicamente”: A la Austríada que compuso en otavas Juan Rufo, jurado i natural de la ciudad de Córdova», aunque también en f. 226r, Sonetos amorosos, «Soneto 47. A Juan Rufo, jurado de Córdova i célebre poeta» («Culto jurado, si mi vella dama»).

\section{A MODO DE CONCLUSIÓN}

A la vista de lo expuesto en páginas precedentes, estamos ante un cancionero de autor (o de poesías varias) en dos tiempos, cancionero-antología bipartito e incluso dos antologías complementarias, en un proyecto editorial realizado por Angulo, en distintas fases de redacción, con el objeto de enaltecer la fama póstuma de Góngora y difundir su poesía, reivindicando además algunas de sus facetas, como la de poeta «a lo divino» y «heroico». Destaca, entre otros rasgos que caracterizan dicho plan editorial, su voluntad, aunque fallida, de restituir el original de Góngora a partir de fuentes heterogéneas e informantes varios, por lo general sin mencionar, con las excepciones de Salvador de Chavarría, Luis de Babia y Juan de Villegas; o lo que es lo mismo, asistimos a una edición frustrada debido a sus altas pretensiones, de ahí los poemas sin transcribir, notas inconclusas o anunciadas sin llegar a término, etc. Incluso en ocasiones no faltan por parte de Angulo interpretaciones poco acertadas de los poemas con graves problemas de atribución autorial al fondo, entre otros errores, si bien los manuscritos de 1639 y 1640

45 Rom. 4. «A S. Teresa de I H S., fundadora de la reforma de carmelitas descalços. Salió en la justa literaria de su beatificación a 2 de otubre, año 1615, en Córdova i en nombre del Ldo. [espacio en blanco], vicario que a la saçón era en la villa de Trasierra. Premiáronlo con unas medias de seda negras. Fue uno de los jueces de la Justa el mismo D. Luis de Góng[or]a, i en la distribución de los premios se le dixo: "No nos dexa ir melancólicos el Ldo. [espacio en blanco] con un romance serio i jocoso a ratos; dásele por premio unas medias de seda negras que, aunque de puntos delgados, no tanto que lleguen a los suyos; trairalas los días de fiesta, porque sus filigreses no consienten traerlas cada día". El argumento es vario i se dirá en el de las coplas». Véase: Luis de Góngora (1998 II: 326-338), n. ${ }^{\circ}$ 72, sección Romances de autoría segura. 
ofrecen datos de interés sobre la circulación y recepción de la obra de Góngora. Por lo demás, el proyecto llegó a quedarse sin mecenazgo literario, cuyo prócer bien podría haber sido Pérez de Pulgar y Sandoval, como en otras obras suyas, de ahí la ausencia de dedicatario.

Ahora bien, tras el examen atento del códice nos asaltan interrogantes que habrán de abrir futuras vías de indagación tales como: ¿pudo haber intervenido una censura externa, habida cuenta de la relación de Angulo con el cabildo catedralicio de Granada?; ¿intervino en la concepción y concepto del manuscrito la propia autocensura del editor?, si bien es verdad que se incluyen sonetos satíricos y burlescos, con cierta pátina de ingenio y agudeza verbal, aunque no las letrillas, a las que se alude en ocasiones ${ }^{46}$.

Por el contrario, no se ofrece vida y obra de Góngora, $u$ otros preliminares o posliminares como «acceso» al autor, pero sí algunas pinceladas biográficas del autor cordobés, entre la realidad y la ficcionalización, según se colige del ciclo ayamontino, ciertas huellas que apuntan a un posible diseño creativo concebido como cancionero amoroso de aliento prosopográfico, como también las circunstancias compositivas de sus poemas y algún indicio de cronología interna, esto es en cierta medida como el manuscrito Chacón. Sí ofrece Angulo, como colofón, un acopio de cartas autógrafas de Góngora, que vincula a la edición de su poesía ${ }^{47}$. Del mismo modo, también proporciona al lector, con una voluntad didáctica, una tabla de calado ensayístico para aclarar, en un principio, conceptos oscuros, aunque más bien se encuentra en la línea compositiva de la incluida por Lope de Vega en La Arcadia, con algo de erudición de acarreo ${ }^{48}$.

Otras características de Angulo como lector, editor e intérprete de Góngora en su cancionero vienen dadas por su marcado interés por la fábula mitológica, con visible inclinación, como se ha demostrado, hacia el mestizaje entre los géneros poéticos, como tampoco falta el diálogo intertextual entre la palabra poética de Góngora y la de otros coetáneos, con notas biográficas de por medio, sobre todo, Villamediana y Juan Rufo. En cualquier caso, como resultado, Angulo ofrece al

46 Como en Sonetos varios, f. 243r, en concreto la que comienza «Arroyo, ¿en qué ha de parar», de autenticidad probable: «Soneto 5. Habla consigo mismo en la ausencia q[ue] hiço de la Corte para escusarse la pesadumbre q[ue] le dieran por la letrilla q[ue] hiço: [en blanco] Arroyo, ¿en q[ué] a de parar [...]. Muéstrase escarmentado de hacer letras semejantes, pues no le toca a él la corrección de los pasos agenos. Dice q[ue] se apartará de las gentes i de sus desvíos a una choça, aunq[ue] sean su cama las pajas. Despídese de los jueces i del mundo por librarse de la locura que ay en él. No más moralidades de corrientes».

47 En este sentido, se encuentra ubicado en una posición privilegiada entre los comentaristas coetáneos para la difusión de su modelo.

48 Lo estudio en «Erudición y cultura en la Égloga fúnebre a D. Luis de Góngora, de Martín de Angulo y Pulgar» (en prensa $c$ ). 
lector un manuscrito autógrafo base para sus obras en defensa de Góngora, o sea Epístolas satisfactorias y Égloga fúnebre, con algún toque de codex excerptorius o zibaldone poético, remozado de pensamientos estéticos, reflexiones críticas y juicios valorativos. De hecho, la compilación y factura del manuscrito autógrafo es fruto más bien de un aficionado a la poesía de Góngora, al que intenta imitar creativamente en la Égloga fúnebre, concebida como un centón, pero también de un coleccionista de versos (y documentos) gongorinos. No obstante, los llega a ordenar en calidad de editor, aunque no de manera demasiado sistemática y en una suerte de pasatiempo lúdico, como un centón o mosaico literario entre la realidad y la ficción con el objeto de demostrar su agudeza o ingenio estético, venciendo así la hermética dificultad y oscuridad críptica de su modelo.

Ahora bien, como contrapunto, llama la atención la ausencia en el códice de las Soledades, que bien podría haber figurado como granada culminación del segundo volumen, poniendo todavía más de relieve el perfil literario de Góngora «heroico», esto es, al igual que sucede con el Polifemo en el primero, aunque sí se alude al poema en algunas notas de Angulo $^{49}$. En cambio, sí se editan el $\mathrm{Pa}$ negírico al Duque de Lerma, con sus respectivos argumentos para cada estancia (ff. 172r ss.), y el Polifemo, aunque falten las letrillas y otras composiciones que se encuentran en las ediciones de Góngora o bien en sus Epístolas y la Égloga fúnebre, como «Perdona al remo, Lícidas, perdona». Con todo, pese a la ausencia de las letrillas, por el contrario, hay referencias intratextuales a las mismas en la macroestructura integral del códice ${ }^{50}$.

Por todo lo señalado hasta el momento, surge otro interrogante para un futuro debate y discusión en la génesis y factura del manuscrito: ¿se trataría de un códice truncado o fragmentario? Sea como fuere, pese a que en el título de los dos manuscritos se anuncia la edición de «casi todas las poesías» de Góngora, a buen seguro como respuesta a la exhaustividad de las ediciones impresas precedentes que trata de superar, Angulo no llegó a alcanzar satisfactoriamente el objetivo perseguido. En contraste, destacan las amplias secciones de romances y sonetos, en sus distintas modalidades, registros y tonalidades genéricas, o sea, de poesías varias, incluso con simetrías estructurales internas en una suerte de ciclos poéticos. El editor atiende además, en su florilegio, ramillete poético o antología

49 Como en la sección de Sonetos varios, ff. 292v-293r, «Soneto 3. Por los q[ue] murmuraron de su primera Soledad» y en el «Soneto 4. Habla con la misma Soledad su poema», o sea «Restituye a tu mudo orror divino» (f. 293r), pero, en este caso, sin comentarios explicativos de Angulo.

50 Por ejemplo, en consonancia con lo ya señalado, en f. 230v, Sonetos satíricos: «Soneto 20. Por el manifiesto agravio que hiço a D. Luis el P. Juan de Pineda, religioso de la Compañía de IHS, que escrivió sobre Job, que aviéndole pedido un soneto [...]»; esto es, «Yo en Justa injusta, expuesto a la sentencia». En la nota contextualizadora dice Angulo: «[...] i de otras causas que diremos en la letrilla [en blanco] satír[ic]a, pla[en blanco] i en su copl. [en blanco] Ay otros gitanos [...]». 
instrumental ${ }^{51}$, destinado también a sus propios fines formativos y creativos, al principio de la varietas mediante alternancia y combinación de estructuras genérico-métricas en sus manuscritos de 1639 y 1640, con diferentes registros y tradiciones: octosílabo y sabor popular, endecasílabo y aliento italianizante, estilemas procedentes de la oralidad y marca culta, romanceamiento/tradición clásica, etc.; en definitiva, un buen banco de prueba y paciencia para un escritor, algo bisoño pero prometedor, que quería medir su talento tomando como referente para la «emulación» a su más admirado modelo.

Es más, a esta ordenación del cancionero lírico o poético cabe añadir, en la arquitectura general de la antología de 1639, la inclusión del teatro de Góngora, representado por Las firmezas de Isabela, en cierta medida entroncando con una floreciente tradición en la que se encuentra por ejemplo el Cancionero de Juan del Encina; o lo que es lo mismo, se trata de la superación del concepto tradicional de cancionero lírico abogando por la renovación en el diasistema propuesto, o sea, en la tensión identificable entre el sistema tradicional del pasado y el nuevo, como la nueva poesía propuesta por Góngora, por el que se apuesta en este proyecto de edición.

En este contexto se distingue, a su vez, el empleo por parte de Angulo de técnicas de trabajo de aliento interdisciplinar, entre las que sobresale el aparato o retórica visual, o sea, una de las principales señas de identidad del modelo que imita, más potente incluso que la musical ${ }^{52}$ en un doble nivel: a) de aliento iconográfico, con la colaboración de Courbes y Heylan, en la línea de Pellicer y Salcedo; b) textual, como se refleja especialmente en las marcas retóricas del Polifemo ${ }^{53}$; mecanismos de canonización publicitaria, en fin, focalizados tanto en Góngora como en Angulo, potenciados además por géneros procedentes de las artes plásticas como el retrato, según se ha analizado. Incardina, en suma, el editor dicha práctica multiforme, poliédrica e interdisciplinar, con vistas a su propia formación, desarrollo y realización personal como escritor «a la estela de Góngora», en la senda del manuscrito Chacón hasta la edición de Gonzalo de Hoces o las Lecciones de José de Pellicer; pero este es todavía un tema lábil y abierto que habrá de ser atendido en otro momento para que, en el estado de la cuestión, no continúe pisando la dudosa luz del día ${ }^{54}$.

\footnotetext{
$51 \mathrm{Y}$ «consultada», al menos parcialmente y de forma indirecta.

52 Como he puesto de relieve en otros artículos, especialmente en «Martín de Angulo, lector de Góngora...» (Escobar en prensa $b$ ).

53 Véase: «Martín de Angulo lector de Góngora...» (Escobar en prensa $b$ ).

54 Que analizo en «La imagen poética de Góngora entre el reflejo especular y el fulgor en la penumbra (a propósito de la retórica visual de Martín de Angulo)» (en prensa $d$ ).
} 


\section{BIBLIOGRAFÍA}

DAZA, Juan Manuel (2015). Contribución al estudio de la polémica gongorina: las «Epístolas satisfactorias» (Granada, 1635) de Martín de Angulo y Pulgar. López Bueno (dir.). Sevilla: Universidad de Sevilla.

Escobar Borrego, Francisco Javier (en prensa $a$ ). «En los márgenes de la controversia literaria: Góngora vindicado por Angulo y Pulgar».

Escobar Borrego, Francisco Javier (en prensa $b$ ). «Martín de Angulo lector de Góngora (con notas inéditas al Polifemo)».

Escobar Borrego, Francisco Javier (en prensa c). «Erudición y cultura en la Égloga fúnebre a D. Luis de Góngora, de Martín de Angulo y Pulgar».

Escobar Borrego, Francisco Javier (en prensa $d$ ). «La imagen poética de Góngora entre el reflejo especular y el fulgor en la penumbra (a propósito de la retórica visual de Martín de Angulo)». En XIII Congreso Bienal de la SRBHP.

Góngora, Luis de (1998). Romances. Antonio Carreira (ed.). Barcelona: Quaderns Crema.

Ponce CÁrdenas, Jesús (2013). «Cebado los ojos de pintura: epigrama y retrato en el ciclo ayamontino». En Juan Matas, José M. ${ }^{a}$ Micó y Jesús Ponce Cárdenas (coords.), Góngora y el epigrama: Estudios sobre las décimas. Madrid/Frankfurt a. M.: Iberoamericana /Vervuert, pp. 143-166.

Recibido: 07/06/2018

Aceptado: 25/06/2018 


\section{雾}

Leer y editar a Góngora en el Siglo de Oro:

Martín de ANGUlo o la ForJa (Frustrada) DE Un CANCIONERo de AUtor

RESUMEN: El presente estudio ofrece un análisis monográfico del manuscrito inédito Varias poesías y casi todas las que compuso... D. Luis de Góngora, de Martín de Angulo y Pulgar, custodiado en la Fundación Bartolomé March (B87-V3-10). Con fecha de 16391640 , constituye una suerte de cancionero de poesías varias o antología preparada por este autor con la voluntad de difundir la obra de Góngora, canonizarlo y de paso posicionarse él mismo, respecto a la nutrida galería o elenco de eruditos comentaristas, en un lugar privilegiado de la república de las letras. Sin embargo, pese a desafiar a los editores precedentes de Góngora e incluso entrar en discordia interpretativa con otros destacados actantes de la polémica literaria, por su ambicioso fuste, el proyecto acabaría inconcluso y sin llegar a buen puerto editorial.

Palabras clave: Luis de Góngora, Martín de Angulo y Pulgar, polémica gongorina, cancionero, Siglo de Oro.

\section{READ AND EDIT GÓNGORA IN THE GOLDEN CENTURY:}

\section{Martín de ANGULO or the Forge (Frustrated) of a SONG OF AUTHOR}

ABSTRACT: The present study offers a monographic analysis of the unpublished manuscript Varias poesías y casi todas las que compuso... D. Luis de Góngora, Martín de Angulo y Pulgar, guarded at the Fundación Bartolomé March (B87-V3-10). With a date of 16391640, it constitutes a kind of poetry songbook or anthology prepared by this author with the aim of spreading the work of Góngora, canonizing it and, in turn, position himself, with respect to the large gallery or cast of commentator scholars, in a privileged place of the Republic of letters. However, despite challenging the previous editors of Góngora and even enter into interpretative discord with other prominent actants of the literary polemic, for its ambitious fuste, the project would end unfinished and without reaching a good publishing port.

KEYWORDS: Luis de Góngora, Martín de Angulo y Pulgar, controversy about Góngora, poetry songbook, Golden Age. 


\section{Edad de Oro. Revista de Filología Hispánica}

ISSN: 0212-0429 - ISSNe: 2605-3314 <https://revistas.uam.es/edadoro/index>

Edad de Oro es uno de los máximos referentes en el área de investigación en Filología Hispánica, especialmente de los siglos XVI y XVII. Goza de un amplio reconocimiento en el ámbito académico internacional. Desde 1982 publica ininterrumpidamente, con una periodicidad anual, colaboraciones científicas de los principales especialistas de diversos centros nacionales y extranjeros. Con un público compuesto esencialmente por investigadores y expertos de todo el mundo, se dirige a cualquier persona interesada en las nuevas corrientes de los estudios humanísticos de su campo.

Dirección:

María Jesús Zamora Calvo

(Univ. Autónoma de Madrid)

Subdirección:

José Antonio Llera Ruiz

(Univ. Autónoma de Madrid)

Secretaría:

Raquel Arias Careaga

(Univ. Autónoma de Madrid)

Consejo de redacción:

Cecilia López-Ridaura

(ENES. Morelia / Univ. Nacional

Autónoma de México)

José Luis Ocasar Ariza

(Univ. Autónoma de Madrid)

Rocío Pérez Gironda

(Univ. Autónoma de Madrid)

Carolina Fernández Cordero

(Iberoamericana-Vervuert)

Admisión de originales:

María Jesús Zamora Calvo

Edad de Oro

Universidad Autónoma de Madrid

Facultad de Filosofía y Letras

Departamento de Filología Española

Campus Cantoblanco

28049 Madrid (España)

Tfno. (+34) 914976886

Correo-e: mariajesus.zamora@uam.es

Distribución, suscripción y venta:

Servicio de Publicaciones de la UAM

Universidad Autónoma de Madrid

28049 Madrid (España)
Intercambio de publicaciones:

Biblioteca de Humanidades

Universidad Autónoma de Madrid

28049 Madrid (España)

Comité científico:

Carlos Alvar (Université de Gèneve)

Ignacio Arellano (Univ. de Navarra)

Alberto Blecua

(Univ. Autónoma de Barcelona)

Jean Canavaggio

(Université Paris Nanterre)

Aurora Egido (Univ. de Zaragoza)

Víctor García de la Concha (RAE)

Luciano García Lorenzo (CSIC)

Joaquín González Cuenca

(Univ. de Castilla la Mancha)

Agustín de la Granja López

(Univ. de Granada)

Begoña López Bueno (Univ. de Sevilla)

Michel Moner

(Universitè Toulouse - Jean Jaurès)

Joan Oleza (Univ. de Valencia)

Alfonso Rey

(Univ. de Santiago de Compostela)

Lina Rodríguez Cacho

(Univ. de Salamanca)

Leonardo Romero Tobar

(Univ. de Zaragoza)

Aldo Ruffinatto

(Università degli Studi di Torino)

Lía Schwartz

(City University of New York)

Han colaborado en este volumen:

Departamento de Filología Española

(UAM)

Facultad de Filosofía y Letras (UAM)

Edad de Oro se recoge en las siguientes bases de datos y directorios: DICE; HLAS; MLA International Bibliography; PIO; ISOC-CSIC; DIALNET; SUMARIS CBUC; ULRICH'S.

Se encuentra evaluada en: SCOPUS: Q2; SCImago: SJR 2017 0.11, H Index 4; ERIH Plus: category A; CIRC: categoría C; RESH: 0.162; MIAR: ICDS 2017 10.0; CARHUS Plus+: C; LATINDEX. 


\section{EDAD DE ORO}

Revista de Filología Hispánica XXXVII

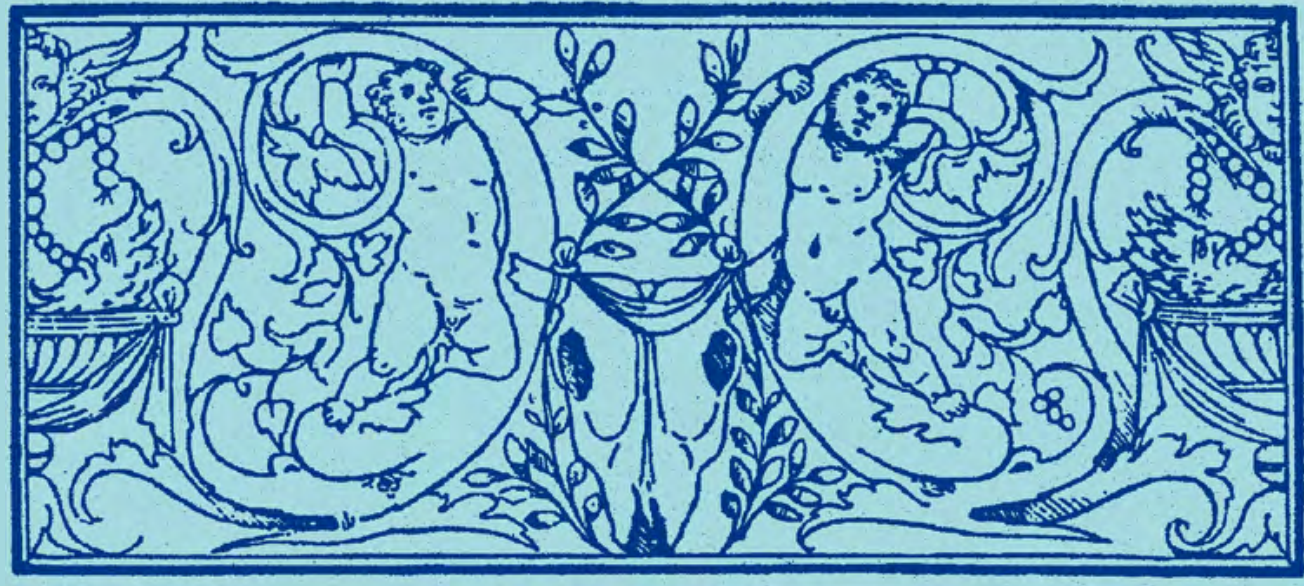

\section{DEPARTAMENTO DE FILOLOGÍA ESPAÑOLA}

EDICIONES DE LA UNIVERSIDAD AUTÓNOMA DE MADRID 